\title{
Particulate Matter concentrations in a new section of metro line: a case study in Italy
}

\author{
A. Cartenì ${ }^{1} \&$ S. Campana ${ }^{2}$ \\ ${ }^{1}$ Department of Civil, Construction and Environmental Engineering, \\ University of Naples Federico II, Italy \\ ${ }^{2}$ Department of Industrial Engineering and Information, \\ Second University of Naples, Italy
}

\begin{abstract}
All round the world, many studies have measured elevated concentrations of Particulate Matter (PM) in underground metro systems, with non-negligible implications for human health due to protracted exposition to fine particles. Starting from this consideration, the aim of this research was to investigate what is the "aging time" needed to measure high PM concentrations also in new stations of an underground metro line. This was possible taking advantage of the opening, in December 2013, of a new section of the Naples (Italy) line 1 railways. The Naples underground metro line 1 before December 31 was long about $13 \mathrm{~km}$ with 14 stations. The new section, opened in December, consists of 5 new kilometres of line and 3 new stations. During the period December 2013January 2014, an extensive sampling survey was conducted to measure $\mathrm{PM}_{10}$ concentrations both in the "historical" stations and in the "new" ones. The results of the study are twofold: a) the $\mathrm{PM}_{10}$ concentrations measured in the historical stations confirm the average values of literature; b) just a few days after the opening of the new metro section, high $\mathrm{PM}_{10}$ concentrations were also measured in the new stations with average $\mathrm{PM}_{10}$ values comparable (from a statistical point of view) with those measured in the historical stations of the line. This result suggests that $\mathrm{PM}_{10}$ pollution in the historical section is delivered by the motion of the trains, almost immediately, into the new section of the line ("piston effect").
\end{abstract}

Keywords: Particulate Matter, PM, underground rail, transport microenvironment, indoor quality. 


\section{Introduction}

In urban areas, the transport sector contributes in the range of $20 \%-40 \%$ in terms of Particulate Matter (PM) emissions. To reduce this incidence, transport planners agree that one of the most effective sustainable transport policies to reduce $\mathrm{PM}$ emissions is the use of an underground metro system because it is based on electric vehicles and has high transport capacity (high efficiency in terms of passenger moved per hour and per vehicle). Furthermore, quality in public transport (e.g. low emissions, comfort, aesthetic standard of the terminals, safety and security) has become an explicit design variable for urban sustainable mobility [1-5]. However, all round the world, many studies have measured elevated concentrations of Particulate Matter (PM) in underground metro systems. Although reported results are not always directly comparable, because of differences in measurement instruments and methods, chemical and size characteristics of Particulate Matter, duration of the measurements and the type of environment investigated (e.g. inside train, ground/underground platform, inside station), all the studies conclude that the underground PM concentrations are consistently higher than in external urban ambient (outdoor), of a factor between 2 to 8 for the station platforms measures.

With respect to the $\mathrm{PM}_{10}$ concentrations measured on station platforms (that is the type of environment investigated in this paper), high Particulate Matter concentrations have been measured in many subway systems all round the world (figure 1), such as in Stockholm [6], Rome [7], Seoul [8, 9], Paris [10], Barcelona [11], Milan [12] and Budapest [13]. Johansson and Johansson [6] and Ripanucci et al. [7] observed that average $\mathrm{PM}_{10}$ concentrations on the platforms in Stockholm and Rome underground are the higher in the world with values of 469 and $407 \mu \mathrm{g} / \mathrm{m}^{3}$ respectively (with maximum values measured of 722 and $877 \mu \mathrm{g} / \mathrm{m}^{3}$ respectively). Also other authors estimated very high $\mathrm{PM}_{10}$ concentrations, for example Raut et al. [10], Querol et al. [11] and Colombi et al. [12] have measured levels of $\mathrm{PM}_{10}$ in stations platforms of Paris, Barcelona and Milan up to 5 times higher than the ones measured in external ambient (outdoor). The most "green" underground metro systems are in Taipei, Seoul and the youngest one of Los Angeles (opened in 2000 [14]). For the first two metro system, Cheng et al. [15] and Jung et al. [16] have estimated low $\mathrm{PM}_{10}$ concentration probably because these metro system are equipped with platform screen door system that is an useful instrument to reduce Particulate Matter concentrations on the platforms because create a screen between the platform and the train/tunnel. This system is relatively a new addition to many metro systems around the world, some having been retrofitted from a traditional one.

Finally, anticipating one of the research results, the average $\mathrm{PM}_{10}$ concentration measured in Naples metro system is lower than $31 \%$ with respect to the other European ones.

Starting from these considerations, the aim of this research is to investigate what is the "aging time" needed to measure high $\mathrm{PM}_{10}$ concentrations also in new stations of an underground metro line. This was possible taking advantage of the 


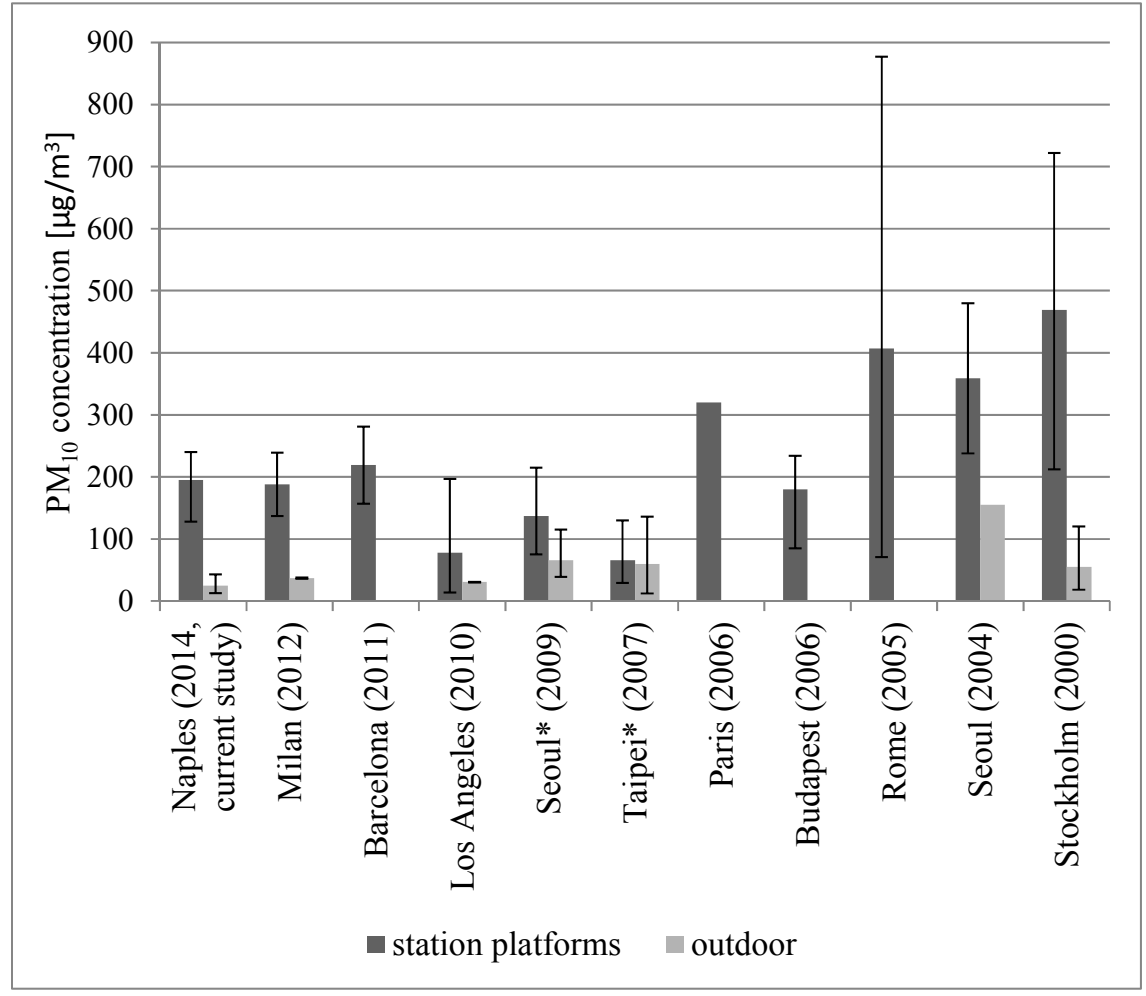

* underground metro with platform screen door system.

Figure 1: Range (min. vs. max) and average $\mathrm{PM}_{10}$ concentrations for different under-ground metro system: station platform against urban ambient (outdoor) measures (in parentheses is the year of the study).

opening, in December 2013, of a new section of the Naples (Italy) line 1 railways.

The paper is organized as follows: Section 2 describes the 2 experimental methodologies; Section 3 presents the main survey results. Finally, the conclusions and research perspectives are reported in Section 4.

\section{Experimental methodology}

\subsection{Case study}

As said, the case study is the Naples line 1 metro system. Naples is one of the most high population density cities with about 1 million of inhabitants and a population density of about 8,100 people/Kmq. These socio-economics and territorial characteristics make this city particularly suitable for a public transport system based on railway (Transit Oriented Development; (e.g. [5]). For over 20 years an integrated planning project based on the use of railways station has been 
set out in Naples. Today within the urban area there are 9 metropolitan lines and it is estimated that by the end of the overall planning project, $60 \%$ of Neapolitans will have a metro station less than 500 metres close.

The Naples metro line 1 (Figure 2) before December 31 was long - about 13 $\mathrm{km}$ with 14 stations. The new section, opened in December, consist in 5 new kilometres of line and 3 new stations.

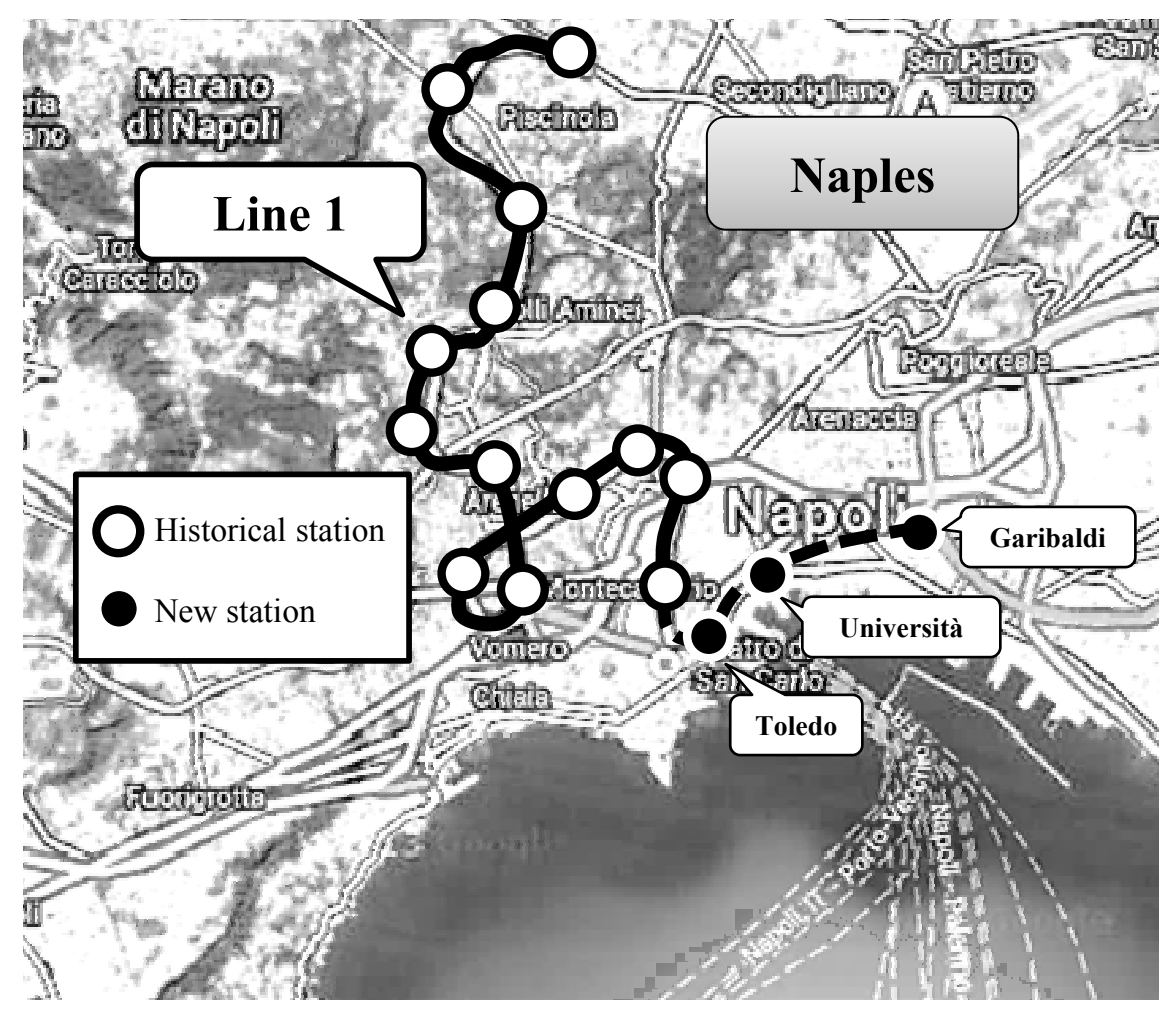

Figure 2: $\quad$ Line 1 of the Naples metro system.

\subsection{Monitoring instrument and measure campaigns}

The Aerocet 531 aerosol particulate monitor (Figure 3) is a particulate mass monitor and particle counting all in a single unit (for more details see also AEROCET 531 Operation Manual [17]). This instrument is small, handy and equipped with portable rechargeable battery (6V Ni-MH).

This instrument is also provided with an iso-kinetic probe, vacuum pump, processor electronics and of relative humidity/temperature sensor (optional). Sessions are recorded in the unit's internal memory and can be transferred to PC through with serial port (RS-232 or RS-485 serial communication) and subsequently processed with the supplied software for the initial management of the data collected on Windows Operation System, or printed directly with the optional portable printer. 
When used as a mass profiler the AEROCET 531 provides a fast indication of particulate mass concentration per cubic meters of sampled air for the most commonly tested particle size fractions. Each sample takes 120 second, after the Aerocet displays the values of $\mathrm{PM}_{1}, \mathrm{PM}_{2.5}, \mathrm{PM}_{7}, \mathrm{PM}_{10}$ and Total Suspended Particulates (TSP). Mass conversion is made using standard conversion factors, or by using your own programmable factors based on unique conditions (KFactor).

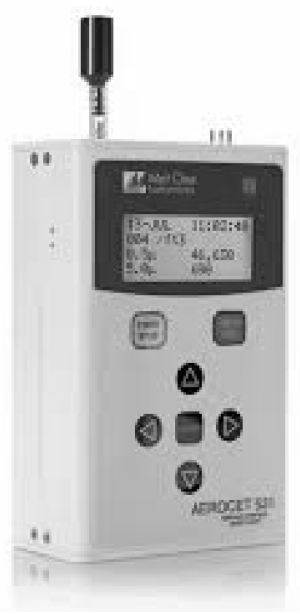

Figure 3: $\quad$ The Aerocet 531 aerosol particulate monitor instrument.

Using a laser-diode-base optical sensor, the Aerocet 531 uses light scatter technology to distinguish, measure, and count particles - larger than 0.5 microns. This detected information can be altered into particle mass using mass-density conversion factors, or may be displayed as particles per size range, depending on how the instrument is configured.

The optional Relative Humidity/Temperature Sensor may be added at anytime; the Aerocet 531 will automatically enable the measurements to the display screen and to the data logger.

The Aerocet 531 comes with an iso-kinetic probe that attaches to its inlet nozzle with the short piece of Tygon tubing provided. The length of the Tygon tubing going from the inlet of the Aerocet 531 to the isokinetic probe can be increased if necessary. However, longer lengths can burden the pump and slow the sample flow rate or cause premature pump failures, so in this survey the tube hasn't been changed.

The iso-kinetic probe helps reduce count errors related to the sample flow velocity and the aerodynamics of small particles.

The instrument could be used as a particulate mass monitor for different applications:

- process control monitoring in sawmills, grain elevators, quarries etc.;

- mines and ore processing plants;

- indoor and outdoor air quality studies (aim of this study); 
- finding leaks and sources of contamination air ducts and filtration systems;

- concerned citizen groups that want to do their own air quality studies;

- event monitoring, fence line monitoring;

- epidemiological studies.

During the period December 2013-January 2014, an extensive sampling survey was conducted to measure $\mathrm{PM}_{10}$ concentrations both in the "historical" stations and in the "new" ones during the peak-hour of the business days. Outdoor measurements of these stations were also conducted to compare air quality both outdoor and indoor. As said Naples Line 1 was monitored and in particular the samples were measured $\mathrm{PM}_{10}$ concentrations at metro stations of: Vanvitelli, Museum, Dante, Toledo, University and Garibaldi. The last three are identifiable as "new stations", the remaining stations as "historical".

The $\mathrm{PM}_{10}$ levels were measured by an expert carrying the AEROCET 531 in a backpack, the station platforms monitored. The T/RH sensor and the upper end of the Tygon tube of the probe iso - kinetics were carefully arranged outside of the backpack. Furthermore, was used the standard Tygon tube (less than $5 \mathrm{~cm}$ ) without the need for extension cords so as to avoid deposit of particles that could affect the subsequent measurements. All air samples were collected roughly 1.65 $\mathrm{m}$ from the platform floor and the logging interval for all measurements was set at $2 \mathrm{~min}$.

To make the results homogeneous and comparable, measurements were always carried out on days of clear weather with surface temperatures in the seasonal averages $12-18^{\circ} \mathrm{C}$ and the average low wind conditions (wind speed $<10 \mathrm{~km} / \mathrm{h}$ ). Obviously, the temperatures on the platform, being underground, are slightly different from those of street level; these temperatures are on average $16-17^{\circ} \mathrm{C}$.

\section{Survey results: mass concentrations}

The results of measurements are summarized in Table 1 and in Figure 4. The average $\mathrm{PM}_{10}$ concentration measured in the stations monitored ranges between 172 and $262 \mu \mathrm{g} / \mathrm{m}^{3}$ with a standard deviation of between 17 and $54 \mu \mathrm{g} / \mathrm{m}^{3}$. The maximum value of $\mathrm{PM}_{10}$ concentration was measured in the new station University and is equal to $340 \mu \mathrm{g} / \mathrm{m}^{3}$.

In order to verify if there is a statistical difference between the values measured in the historic stations (Vanvitelli, Museum and Dante) and in the new ones (Toledo, University, and Garibaldi) a sample t-test was performed. A significance level of 0.05 was used for all statistical tests. Statistical results indicate no differences among data measured both in historical and new station platforms. This means that just after one week after the opening of the new metro section (Toledo-Università-Garibaldi) high values $\mathrm{PM}_{10}$ concentration were measured. This result suggests that PM pollution in the historical section is carried by the movement of trains, almost immediately, in the new section of the line (like a "piston effect"). 
Table 1: Distribution of indoor (station platform) and outdoor $\mathrm{PM}_{10}$ mass concentrations (in $\mu \mathrm{g} / \mathrm{m}^{3}$ ) measured (December 2013 - January 2014).

\begin{tabular}{|c|c|c|c|c|c|c|c|}
\hline & & Hist & ical s & tions & $\begin{array}{r}N \\
\text { (afte } \\
\text { th }\end{array}$ & $\begin{array}{l}\text { statio } \\
\text { week } \\
\text { penin }\end{array}$ & om \\
\hline & $\begin{array}{r}\text { Station } \\
\text { platform }\end{array}$ & 离 & $\stackrel{8}{\stackrel{D}{\Xi}}$ & 节 & $\frac{0}{\frac{0}{0}}$ & & שู \\
\hline \multirow{4}{*}{$\begin{array}{l}\text { Daytime, } \\
\text { peak hour, } \\
\text { business } \\
\text { day }\end{array}$} & Min & 129 & 128 & 153 & 117 & 195 & 134 \\
\hline & Average & 179 & 172 & 178 & 172 & 262 & 207 \\
\hline & Max & 229 & 240 & 194 & 220 & 340 & 215 \\
\hline & St. Dev. & 39 & 36 & 17 & 31 & 54 & 50 \\
\hline
\end{tabular}

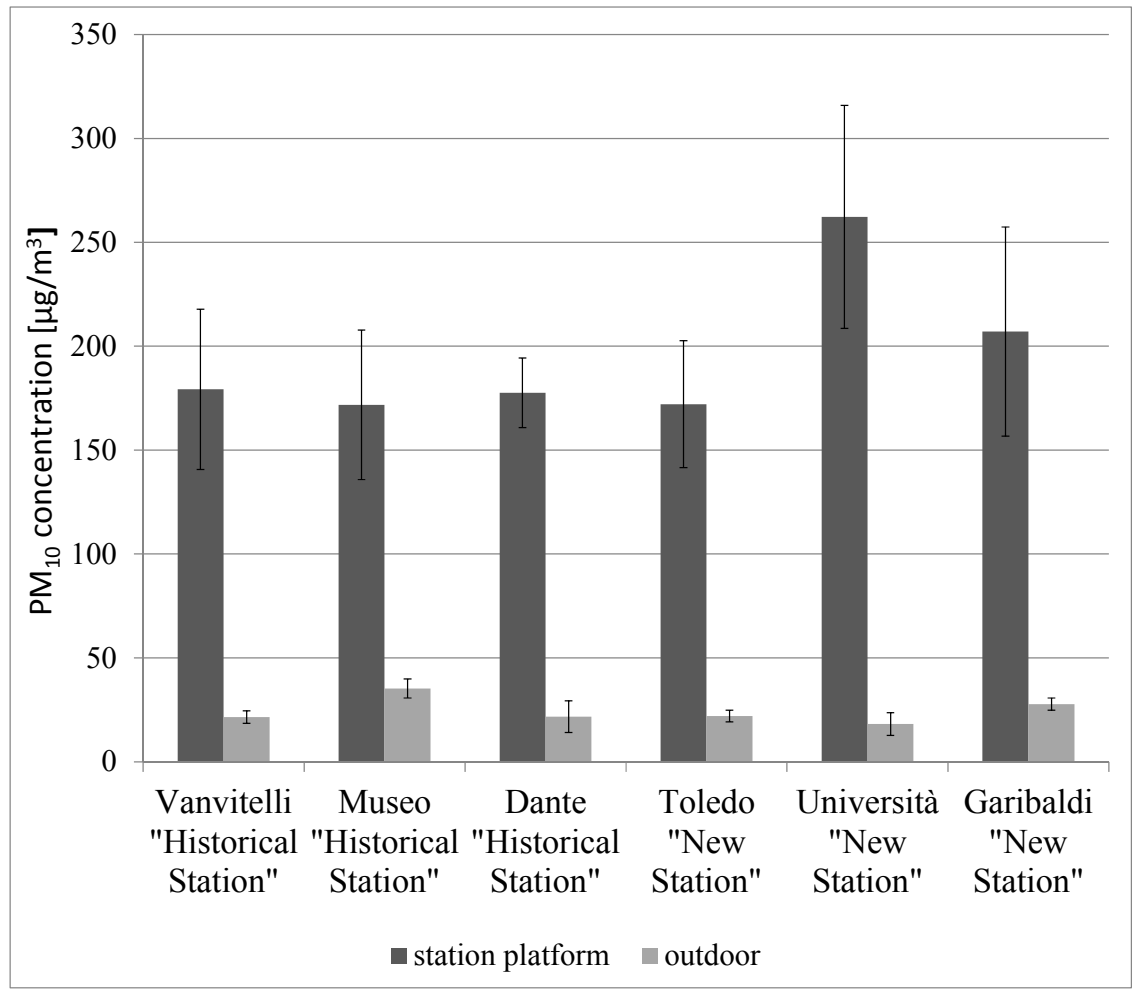

Figure 4: Distribution of indoor (station platform) and outdoor $\mathrm{PM}_{10}$ mass concentrations (in $\mu \mathrm{g} / \mathrm{m}^{3}$ ) measured (December 2013-January 2014). 
Furthermore, samples t-test was also performed to test differences in PM levels between indoor metro stations and outdoor environment. The results obtained show that concentrations measured in outdoor ambient are statistically different with respect to the indoor ones.

In Figures 5 and 6 the $\mathrm{PM}_{10}$ concentrations measured during the morning peak hour of an average business day on both a new station are reported

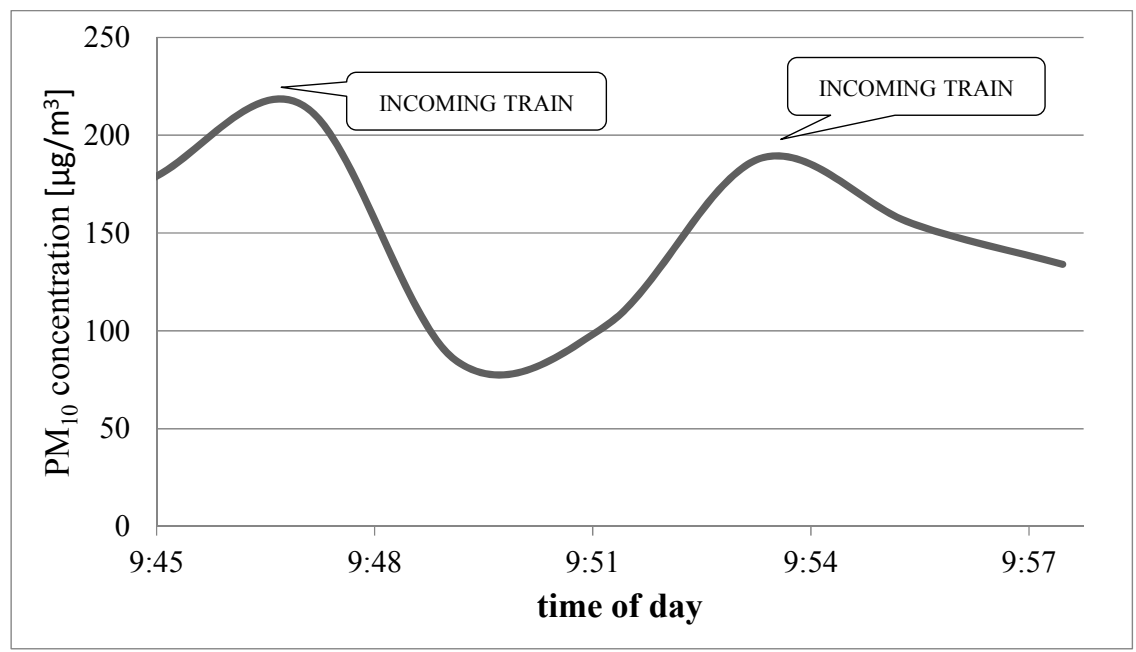

Figure 5: Business day average $\mathrm{PM}_{10}$ mass concentrations (in $\mu \mathrm{g} / \mathrm{m}^{3}$ ) measured during the peak-hour on the Garibaldi station platform (new station).

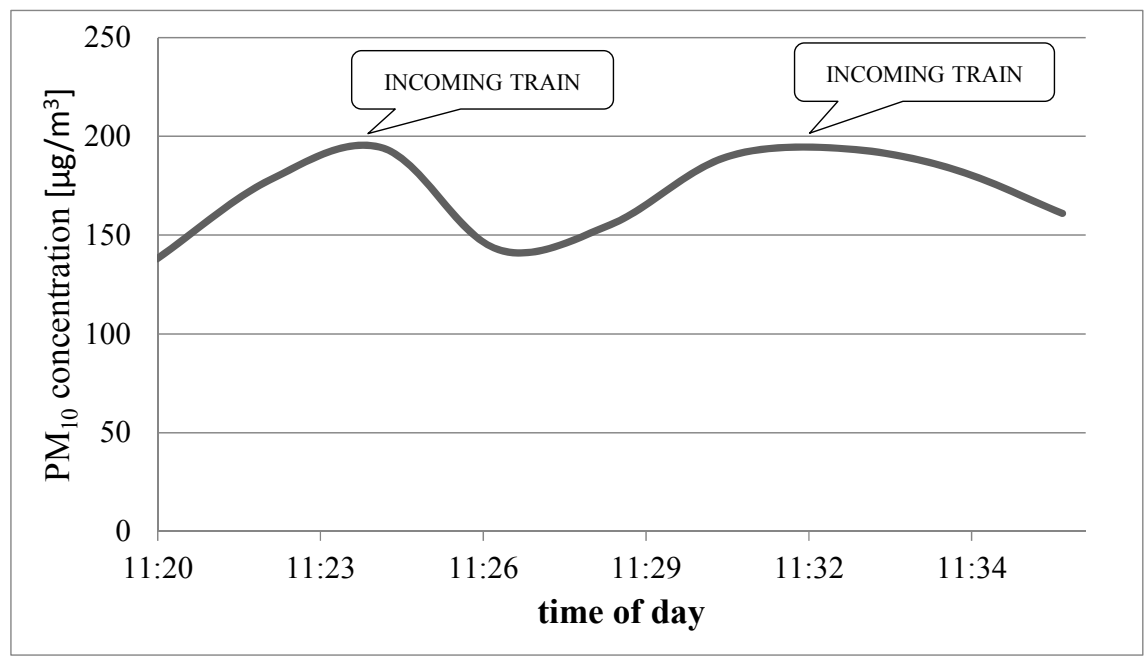

Figure 6: Business day average $\mathrm{PM}_{10}$ mass concentrations (in $\mu \mathrm{g} / \mathrm{m}^{3}$ ) measured during the peak-hour on the Dante station platform (historical station). 
(Garibaldi station platforms) and an historic one (Dante station platform). As reported, the highest concentration values are measured when the trains arrive in the station platform (up to $42 \%$ greater than the average values measured on the platform). These results suggest that the passage of trains is the main cause of particulate concentration on the station platform, presumably with a two-fold action, as observed also in Colombi et al. [12]; particles are directly produced from the wear of metal parts and are also re-suspended by the turbulence induced by train passage. These results were observed also in Johansson and Johansson [6] and Salma et al. [13] that reported the PM levels in metro stations closely follow the train frequency. Also these experimental results indicate that PM levels can be induced by the resuspension due to train movement.

Finally we have estimated the daily average "exposition time" to these high $\mathrm{PM}_{10}$ concentrations for the passengers of the Naples metro system. Through the transport simulation models developed for the Naples metropolitan area (for details see [18-21]) we have estimated that every day the Linea 1 is used by over one hundred thousand passengers and the average daily time spent for waiting the trains on the platform (for a round trip) is more than 18 minutes per passengers.

\section{Conclusions and research perspectives}

All round the world, many studies have measured elevated concentrations of Particulate Matter in underground metro systems, with non-negligible implications for human health due to protracted exposition to fine particles. In all investigated environments, concentrations are consistently higher than in ambient air (outdoor) up to a factor of 8 on the platform.

The aim of this research was to investigate what is the "aging time" needed to measure high PM concentrations also in new stations of an underground metro line.

The results of the study are twofold: a) the PM concentrations measured in the historical stations confirm the average values of literature; b) just few days after the opening of new metro section, high PM concentrations was measured also in the new stations with average PM values comparable (from a statistical point of view) with those measured in the historical stations of the line. This result suggests that PM pollution in the historical section is delivered by the motion of the trains, almost immediately, into the new section of the line ("piston effect").

Finally, the average $\mathrm{PM}_{10}$ concentration measured in Naples metro system is lower than $31 \%$ with respect to the others European metro systems monitored.

These results suggest that metro PM concentration should be considered as an explicit design variable in transportation planning (e.g. [22]).

Starting from these results, the research perspectives will be:

- integrate the survey measures estimating also the Particulate Matter concentrations on board train; 
- replicate the methodology proposed and applied in this study for the estimation of the Particulate Matter concentrations for a port container terminal. Furthermore, starting from the measures results one of the research perspective will be to introduce explicit handling vehicle pollutant attributes in simulation models (e.g. [23-25]).

\section{References}

[1] Cartenì, A., Galante G., Henke I., The catchment area of an high architectural railways station: a case study in Italy. WIT Transactions on the Built Environment, 135, 2014.

[2] Cascetta E., Cartenì, A., Carbone A., The quality in public transportation. The campania regional metro system [La progettazione quality-based nel trasporto pubblico locale. Il sistema di metropolitana regionale delia Campania]. Ingegneria Ferroviaria, 68 (3), pp. 241-261, 2013. ISSN: 0020-0956.

[3] Cascetta, E., Cartenì, A., A quality-based approach to public transportation planning: theory and a case study. International Journal of Sustainable Transportation, Taylor \& Francis, Vol. 8, Issue 1. pp. 84-106, $2014 \mathrm{~b}$. DOI: $10.1080 / 15568318.2012 .758532$.

[4] Cascetta, E., Cartenì, A., The hedonic value of railways terminals. A quantitative analysis of the impact of stations quality on travellers behaviour. Transportation Research Part A vol. 61, pp. 41-52, 2014a. DOI:10.1016/j.tra.2013.12.008.

[5] Cascetta E., Cartenì, A., Henke I., Stations quality, aesthetics and attractiveness of rail transport: empirical evidence and mathematical models [Qualità delle stazioni, estetica e attrattività del trasporto ferroviario: evidenze empiriche e modelli matematici]. Ingegneria Ferroviaria, 2014. ISSN: 0020-0956.

[6] Johansson, C., Johansson, P.A., Particulate matter in the underground of Stockholm, Atmospheric Environment 37, pp. 3-9, 2003.

[7] Ripanucci, G., Grana, M., Vicentini, L., Magrini, A., Bergamaschi, A., Dust in the underground Railway Tunnels of an Italian Town, Journal of Occupational and Environmental Hygiene 3, pp. 16-25, 2006.

[8] Kim, K.Y., Kim, Y.S., Roh, Y.M., Lee, C.M., Kim, C.N., Spatial distribution of particulate matter (PM10 and PM2.5) in Seoul Metropolitan Subway stations, Journal of Hazardous Materials 154, pp. 440-443, 2008.

[9] Jung, H.-J., Kim, B., Ryu, J., Maskey, S., Kim, J.-C., Sohn, J., Ro, C.-U., Source identification of particulate matter collected at underground subway stations in Seoul, Korea using quantitative single-particle analysis, Atmospheric Environment 44, pp. 2287-2293, 2010.

[10] Raut, J.-C., Chazette, P., Fortain, A., Link between aerosol optical, microphysical and chemical measurements in an underground railway station in Paris, Atmospheric Environment 43, pp. 860-868, 2009. 
[11] Querol, X., Moreno, T., Karanasiou, A., Reche, C., Alastuey, A., Viana, M., Font, O., Gil, J., De Miguel, E., Capdevila, M., Variability of levels and composition of PM10 and PM2.5 in the Barcelona metro system, Atmospheric Chemistry and Physics 12, pp. 5055-5076, 2012.

[12] Colombi C., Angius S., Gianelle V., Lazzarini M., Particulate matter concentrations, physical characteristics and elemental composition in the Milan underground transport system, Atmospheric Environment, Volume 70, pp. 166-178, May 2013.

[13] Salma, I., Weidinger, T., Maenhaut, W., Time-resolved mass concentration, composition and sources of aerosol particles in a metropolitan underground railway station, Atmospheric Environment 41, pp. 8391-8405, 2007.

[14] Kam, W., Cheung, K., Daher, N., Sioutas, C., Particulate matter (PM) concentrations in underground and ground-level rail systems of the Los Angeles Metro, Atmospheric Environment 45, pp. 1506-1516, 2011.

[15] Cheng, Y.H., Lin, Y.L., Liu, C.C., Levels of PM10 and PM2.5 in Taipei Rapid Transit System, Atmospheric Environment 42, pp. 7242-7249, 2008.

[16] Jung, H.-J., Kim, B., Ryu, J., Maskey, S., Kim, J.-C., Sohn, J., Ro, C.-U, Source identification of particulate matter collected at underground subway stations in Seoul, Korea using quantitative single-particle analysis, Atmospheric Environment 44, pp. 2287-2293, 2010.

[17] AEROCET 531 Operation Manual, AEROCET-531-9800 REV F, pp. 3$38,1999$.

[18] Bifulco, G.N., Cartenì, A. and Papola, A., An activity-based approach for complex travel behaviour modelling, European Transport Research Review, 2(4), pp. 209-221, 2010. DOI: 10.1007/s12544-010-0040-3.

[19] Cartenì, A., Updating demand vectors using traffic counts on congested networks: A real case application, WIT Transactions on the Built Environment 96, pp. 211-221, 2007. DOI: 10.2495/UT070211.

[20] Cartenì, A. and Punzo, V., Travel time cost functions for urban roads: A case study in Italy, WIT Transactions on the Built Environment 96, pp. 233-243, 2007. DOI: 10.2495/UT070231.

[21] de Luca, S., Cantarella, G.E., Cartenì, A., A macroscopic model of a container terminal based on diachronic networks, Operations Research/ Computer Science Interfaces Series, 46, pp. 285-310, 2009.

[22] D'Acierno, L., Gallo, M., Montella, B. \& Placido, A., Analysis of the interaction between travel demand and rail capacity constraints. WIT Transactions on the Built Environment, 128, pp. 197-207, 2012.

[23] Cartenì, A. and de Luca, S., Analysis and modeling of container handling equipment activities, European Transport - Trasporti Europei, (46), pp. 52-71, 2010. ISSN: 18253997.

[24] Cartenì, A. and de Luca, S., Tactical and strategic planning for a container terminal: Modelling issues within a discrete event simulation approach, Simulation Modelling Practice and Theory, 21(1), pp. 123-145, 2012. DOI: 10.1016/j.simpat.2011.10.005. 
[25] de Luca, S., Cartenì, A., A multi-scale modelling architecture for estimating of transport mode choice induced by a new railway connection: The Salerno-University of Salerno-Mercato San Severino Route [Un'architettura modellistica multi-scala per la stima delle ripartizioni modali indotte da un nuovo collegamento ferroviario: il caso studio della tratta Salerno-Università di Salerno-Mercato San Severino], Ingegneria Ferroviaria, 68 (5), pp. 447-473, 2013. ISSN: 0020-0956. 